\title{
Miocene magnetostratigraphy from Equatorial Pacific sediments (ODP Site 1218, Leg 199)
}

\author{
Luca Lanci $^{\mathrm{a}, \mathrm{b}, *}$, Josep M. Pares ${ }^{\mathrm{c}}$, James E.T. Channell ${ }^{\mathrm{d}}$, Dennis V. Kent ${ }^{\mathrm{e}}$ \\ ${ }^{\mathrm{a}}$ Facoltà di Scienze Ambientali, Università di Urbino, Campus scientifico SOGESTA, Urbino, PU 61029, Italy \\ ${ }^{\mathrm{b}}$ Department of Geological Sciences, Rutgers University, Piscataway, NJ 08854, USA \\ ${ }^{\mathrm{c}}$ Department of Geological Sciences, University of Michigan, 2534 C.C. Little Building, Ann Arbor, MI 48109, USA \\ ${ }^{\mathrm{d}}$ Department of Geological Sciences, University of Florida, 241 Williamson Hall, Gainesville, FL 32611, USA \\ ${ }^{\mathrm{e}}$ Department of Geological Sciences, Rutgers University, Piscataway, NJ 08854 USA, \\ and Lamont-Doherty Earth Observatory, Palisades, NY 10964, USA
}

Received 29 March 2004; received in revised form 16 July 2004; accepted 17 July 2004

Editor: V. Courtillot

\begin{abstract}
Pliocene and Miocene magnetostratigraphy from ODP Site 1218 (Equatorial Pacific) has been obtained by measurements made on u-channel samples, augmented by about 50 discrete samples. U-channel samples were measured at $1 \mathrm{~cm}$ intervals and stepwise demagnetized in alternating fields up to a maximum peak field of $80 \mathrm{mT}$. The component magnetization directions were determined by principal component analysis for demagnetization steps in the $20-60 \mathrm{mT}$ peak field range. A relatively small number of discrete samples were subject to both thermal and alternating field (AF) demagnetization and gave results compatible with u-channel measurements.

Magnetostratigraphy from u-channel samples are compared with shipboard data that were based on blanket demagnetization at peak $\mathrm{AF}$ fields of $20 \mathrm{mT}$. U-channel measurements add more detail to the magnetostratigraphic record and allow identification of thin polarity zones especially in the upper part of the section were the sedimentation rates are very low ( $2 \mathrm{~m} / \mathrm{Myr})$. The component magnetization directions determined from u-channel measurements also gave more reliable and precise estimates of inclination (paleolatitude). The magnetostratigraphy from Site 1218 can be unambiguously correlated with the reference geomagnetic polarity time scale and gives a means of dating the sedimentary sequence. Both Miocene-Pliocene and Oligocene-Miocene stage boundaries were easily identified from the magnetostratigraphic record.

Although calculation of paleomagnetic poles is hindered by the low precision of the cores' azimuthal orientation, the data from both u-channel and discrete samples allow determination of the paleolatitude of the Site through time with good precision. Paleomagnetic data indicate that the paleolatitude of Site 1218 has increased form nearly equatorial latitude in the Oligocene to
\end{abstract}

* Corresponding author. Facoltà di Scienze Ambientali, Università di Urbino, Campus scientifico SOGESTA, Urbino, PU 61029, Italy. Tel./fax: +390722 304295 .

E-mail address: 1lanci@uniurb.it (L. Lanci).

0012-821X/\$ - see front matter (C) 2004 Elsevier B.V. All rights reserved. doi:10.1016/j.eps1.2004.07.025 
its present-day latitude close to $9^{\circ} \mathrm{N}$. Within the precision of the paleomagnetic data, this is in agreement with current predictions of plate motion models based on fixed hotspots.

(C) 2004 Elsevier B.V. All rights reserved.

Keywords: Miocene; magnetostratigraphy; equatorial Pacific; Ocean Drilling Program

\section{Introduction}

The geomagnetic polarity time scale (GPTS) based on oceanic magnetic anomalies and magnetostratigraphy in deep-sea sediments has become fundamental in correlating biozonations and absolute ages (i.e., [1]). Deep-sea sediment cores may provide long and continuous sedimentary records that are not affected by deformation or diagenesis. If drilling does not excessively disturb the sediments, they can also give records of geomagnetic polarity that can be used for global correlation and dating. The Advanced Piston Corer (APC) used by the Ocean Drilling Program (ODP) has been very effective for sampling unconsolidated sediments with minimum disturbance, and the resulting cores often give excellent results in paleomagnetic studies. Moreover, the sediment cores can be azimuthally oriented preserving declination information, which is very important at low latitude where inclination is close to horizontal for both normal and reversed polarities.

The top $165 \mathrm{~m}$ of sediment at ODP Site 1218 , drilled during ODP Leg 199, was cored using the APC technique and gave a particularly continuous record of Earth's magnetic field at a single site. The record from Site 1218 spans from Late Pleistocene to middle Eocene including the Oligocene/Miocene boundary, and has good biostratigraphic control [2]. Combined with that from nearby Site 1219, the magnetostratigraphic record can be extended into the Early Oligocene.

Shipboard magnetostratigraphy at Site 1218 constituted the basis of the chronology for this site, and was the means of precise correlation among the sites of Leg 199. The shipboard polarity stratigraphy was determined from "blanket" demagnetization at a single peak field $(20 \mathrm{mT})$ and the results were clear enough to allow interpretation of most of the polarity sequence. However, many features of the initial polarity record were obscured by the relatively low resolution of the shipboard pass-through magneto- meter. To improve the quality of the magnetostratigraphy, we have carried out stepwise demagnetization of u-channel samples, accompanied by rock magnetic studies. In this paper, we present a high-resolution paleomagnetic record, based on u-channel measurements, from the Miocene section of Site 1218.

\section{Materials and sampling}

\subsection{Drilling Sites}

ODP Site 1218 was cored in the equatorial Pacific Ocean during Leg 199 at $8^{\circ} 53.378^{\prime} \mathrm{N}, 135^{\circ} 22.00^{\prime} \mathrm{W}$ in a water depth of $4811 \mathrm{~m}$. Site 1218 is located on 40-Myr-old crust, and is situated on a basement swell $\sim 3^{\circ}$ north of the Clipperton Fracture Zone in the central tropical Pacific (Fig. 1). Pacific plate motion carried the site across the equator at $\sim 40 \mathrm{Ma}$ based upon a fixed hotspot model (see [3] for 0-5 Ma Pacific hotspot rotation pole and [4] for older poles). Based on this model, the site remained within $2^{\circ}$ of the equator from the time the basaltic crust was formed until $27 \mathrm{Ma}$. The sediments recovered from Site 1218 should therefore record equatorial paleoceanographic conditions from the middle Eocene until the early Oligocene. At Site 1218, a complete sediment sequence was recovered to within $15 \mathrm{~m}$ of basaltic basement. The top $165 \mathrm{~m}$ were cored using the APC system and sediment cores could be azimuthally oriented preserving the declination information. The sediments from this site yielded an excellent record of geomagnetic polarity reversals for the entire Miocene and most of the Oligocene at a single site. Nannofossils and radiolarians indicate that the section is biostratigraphically complete with no apparent hiatuses [2].

The Pleistocene and Miocene sediments at Site 1218 comprise two main sedimentary units [2]. At the top of the sedimentary column is $59 \mathrm{~m}$ of yellowish brown clay with some nannofossils and occasional 


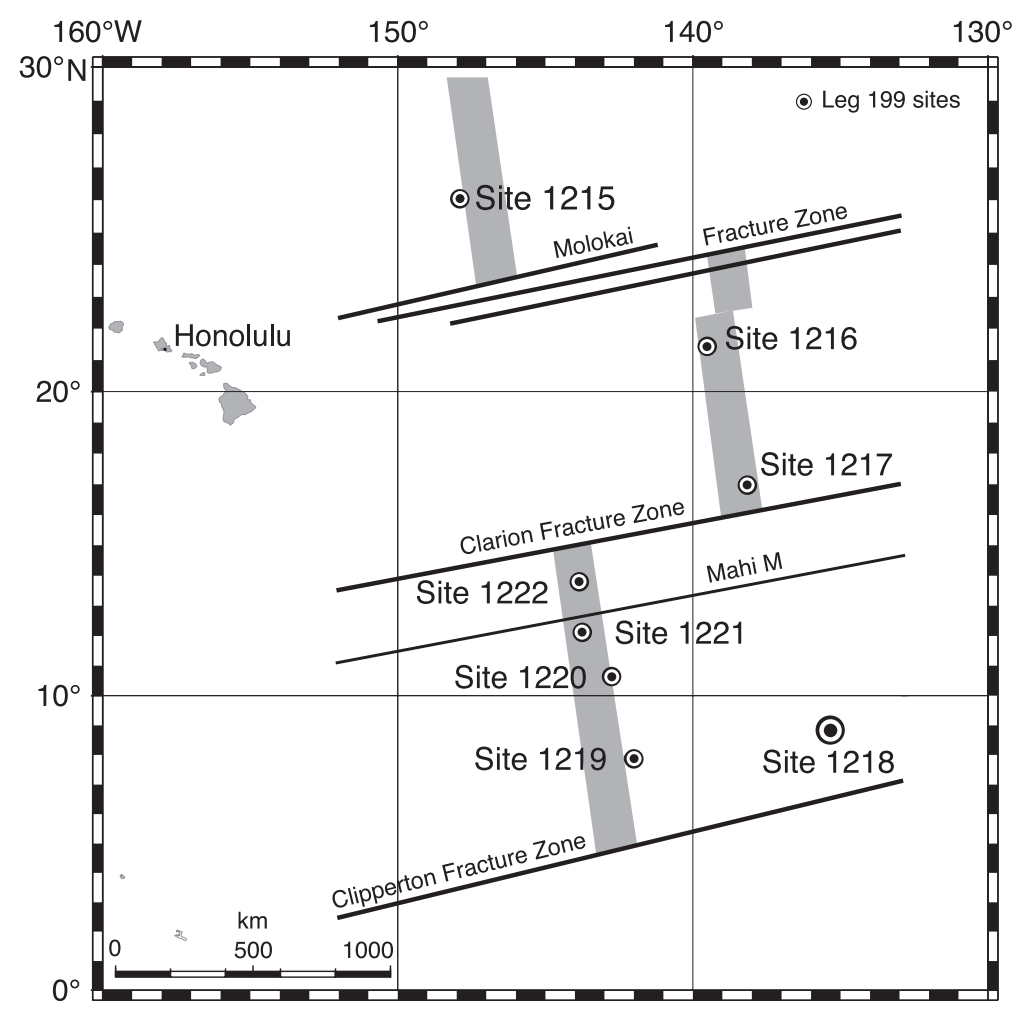

Fig. 1. Location of Site 1218 and other Leg 199 sites.

barren intervals. This upper clay unit is mostly composed of wind-blown dust, clays, and radiolarians, some of which were eroded and reworked from older sediment outcrops. The age of this unit, based on the fossil association [2], is Pleistocene to Middle Miocene. Below this brown clay unit, from 59 to $242 \mathrm{mcd}$ (meters composite depth), the section comprises nannofossils ooze and chalk of Lower Miocene-Oligocene age. The unit has cyclic variations of carbonate content related to orbitally driven changes in insolation that can potentially be used to construct an orbitally tuned Oligocene age model [2].

At Site 1218, planktonic foraminifera occur sporadically through the Lower Miocene sediments with generally less consistent occurrence than other calcareous groups such as benthic foraminifera and calcareous nannofossils. Most samples show at least some dissolution of planktonic foraminifera with preferential preservation of thick-walled, large specimens in many cases. Benthic foraminifera are present throughout the cored interval except in the upper radiolarian clays. Calcareous nannofossils, in contrast, are present at varying concentrations and states of preservation from the uppermost middle Miocene Zone NN8 (CN6; $42 \mathrm{mcd}$ ) to the base of the sediment section [2].

\subsection{Composite section and sampling}

A composite section recovered at Site 1218 was constructed on shipboard using multi-sensor track (MST) data to splice together the cores recovered at Holes 1218A, 1218B and 1218C. U-channel sampling [5] was designed to obtain a continuous sampling of the sedimentary section. Unfortunately, this was not always possible because of previous sampling and therefore the u-channel record has a few gaps. The two major gaps are located from 36.56 to $38.85 \mathrm{mcd}$ and from 82.97 to $83.97 \mathrm{mcd}$. These gaps have been filled by collecting discrete samples and by incorporating shipboard data.

The Miocene section sampled at Site 1218 comprises a total of 62 1.5-m-long u-channel samples collected at the Gulf Coast Repository (GCR) at Texas 
A and M University from Holes 1218A, 1218B, and 1218C. A set of 39 discrete samples $\left(7 \mathrm{~cm}^{3}\right.$ plastic cubes) collected shipboard from Hole 1218A were AF demagnetized and another 29 discrete samples collected at the GCR in the Miocene section of Site 1218 were either thermally or AF demagnetized. In total, 51 discrete samples gave acceptable paleomagnetic directions.

The depth scale used in the paper is the mod scale used in [2] with minor modifications from the results of the magnetostratigraphy, which allowed a better match between cores. Since the mcd scale is subject to interpretation, we also report the depth of polarity reversals using the standard ODP notation of SiteHole-Core-Section number, and centimeter position relative to the Section top, that unequivocally identifies each specimen.

\section{Magnetic measurements}

\subsection{NRM measurements}

Natural Remanent Magnetization (NRM) in uchannel samples was measured at 1-cm intervals and subjected to progressive alternating field (AF) demag- netization. U-channel measurements were made on a 2G Enterprises DC-SQUID pass-through cryogenic magnetometer with $3.5-\mathrm{cm}$ access at the University of Florida. Discrete sample measurements and rock magnetic analysis were performed at the LamontDoherty paleomagnetic laboratory.

A few pilot u-channel samples were AF demagnetized using 14 steps up to a maximum peak AF field of $100 \mathrm{mT}$. After inspection of the results, all subsequent u-channel samples were demagnetized using 10 steps up to a maximum field of $80 \mathrm{mT}$, which was adequate to define the component magnetization in these sediments. The overall number of measured intervals presented in this paper exceeds 9400. The $1-\mathrm{cm}$ interval between measurements was chosen to obtain the maximum resolution that was especially important in very low sedimentation rate sediments like the upper brown-clay unit. However, the response functions of the cryogenic magnetometer pick-up coils have a width of approximately $4 \mathrm{~cm}$ [6] and therefore $1-\mathrm{cm}$ interval measurements are not independent from each other. To improve resolution we have applied data deconvolution techniques $[6,7]$ to minimize the smoothing effect of the pick up coils. To allow deconvolution at the u-channels ends, the 1$\mathrm{cm}$ spaced measurements were begun $10 \mathrm{~cm}$ before a)

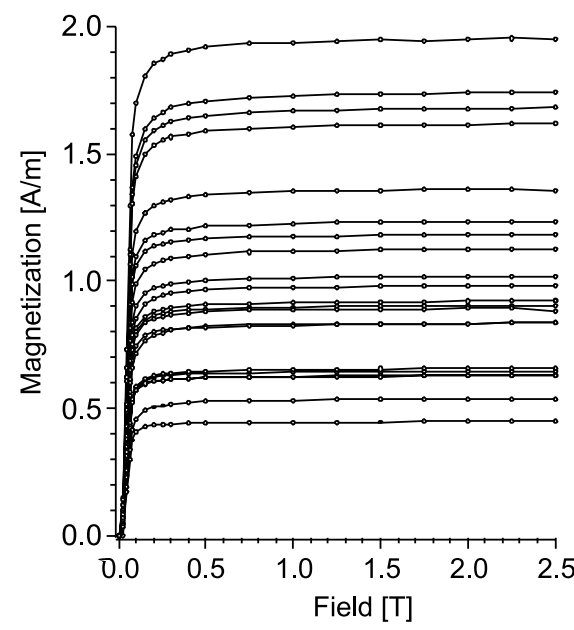

b)

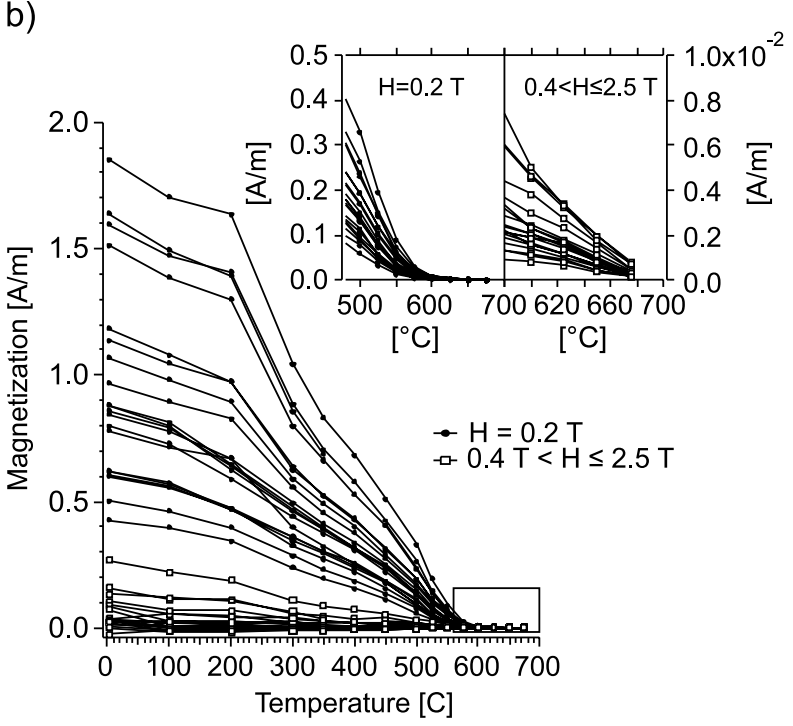

Fig. 2. (a) Progressive IRM acquisition of representative samples from Site 1218. (b) thermal demagnetization of orthogonal IRM produced with different applied fields (see text). The inset shows an enlargement of the final demagnetization steps at the highest temperatures. High and low coercivity fractions are plotted in separate panels for clarity, note the different scales. 
(leader) and continued to $10 \mathrm{~cm}$ after (trailer) the $\mathrm{u}-$ channel ends. A relatively small set of discrete samples were demagnetized thermally with increasing temperature up to $575{ }^{\circ} \mathrm{C}$, at which virtually all the NRM was removed. A second set of discrete samples was AF demagnetized using a procedure equivalent to that used in u-channel samples. Magnetization intensities of NRM in the upper red clays unit is of the order of $1 \times 10^{-2} \mathrm{~A} / \mathrm{m}$ and is reduced to about 2$5 \times 10^{-4} \mathrm{~A} / \mathrm{m}$ after AF demagnetization at $80 \mathrm{mT}$. The lower Miocene carbonate unit has a weaker NRM magnetization of about to $1 \times 10^{-3} \mathrm{~A} / \mathrm{m}$ that is reduced to about $1 \times 10^{-4} \mathrm{~A} / \mathrm{m}$ after demagnetization. The weakest measured magnetizations in these samples are nevertheless significantly above instrumental noise.

\subsection{Magnetic mineralogy}

Information on the magnetic mineralogy was obtained by isothermal remanent magnetization (IRM) acquisition and subsequent thermal demagnetization, and by measuring magnetic hysteresis parameters using an alternating gradient force magnetometer (AGFM). These rock magnetic analyses were made on pilot samples representative of the different lithologies of the core. Pilot samples were magnetized in increasing applied fields up to $2.5 \mathrm{~T}$ and their remanent magnetization measured after each step. After the last step, we applied three orthogonal magnetizations using fields of 2.5, 0.4 and $0.2 \mathrm{~T}$ and subjected the resultant IRM to progressive thermal demagnetization following the method outlined by Lowrie [8]. Here we consider only the low coercivity $(H<0.2 \mathrm{~T})$ and the high coercivity $(H \geq 0.4 \mathrm{~T})$ fractions disregarding the intermediate coercivity component that, in this case, does not give additional information.

IRM acquisition curves (Fig. 2a) show a rapid increase of magnetization; samples are nearly saturated at fields of about $200 \mathrm{mT}$, which indicates that magnetite is the most important carrier of the IRM. The magnetization acquired in fields larger than 300 $\mathrm{mT}$ is a small fraction of the IRM (from $2 \%$ to $4 \%$ ). Thermal demagnetization of the orthogonal IRM shows that the largest fraction of the magnetization is carried by the low coercivity component $(H<0.2 \mathrm{~T})$, which has an unblocking temperature of about $580{ }^{\circ} \mathrm{C}$ as expected for magnetite (Fig. 2b). The high coercivity component of IRM $(H \geq 0.4 \mathrm{~T})$ is almost completely unblocked at $675^{\circ} \mathrm{C}$ and demagnetization trends clearly suggest that hematite is the carrier of this component.

Examples of hysteresis loops from typical samples are shown in Fig. 3a and the hysteresis parameters [9] are plotted in Fig. 3b. All measured samples show loops with very similar shapes and their hysteresis

a)

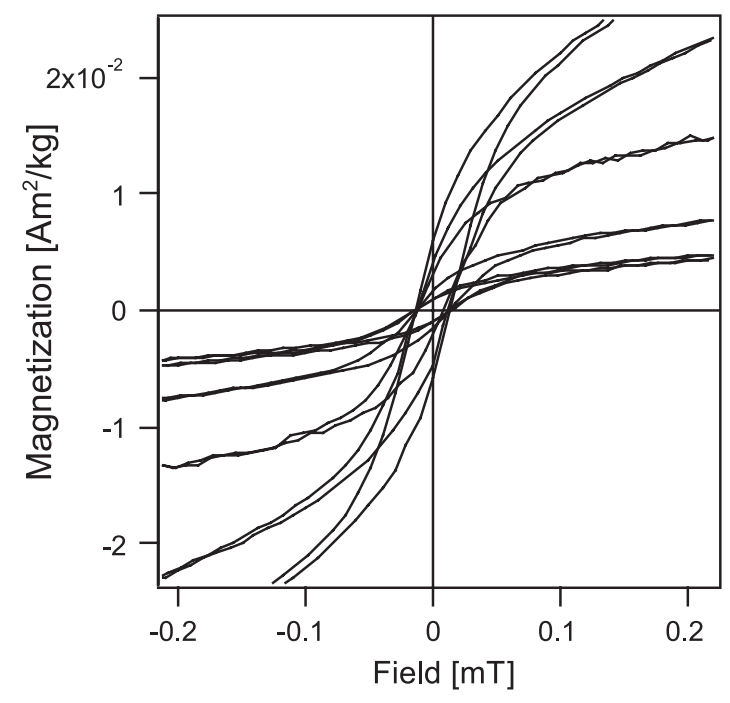

b)

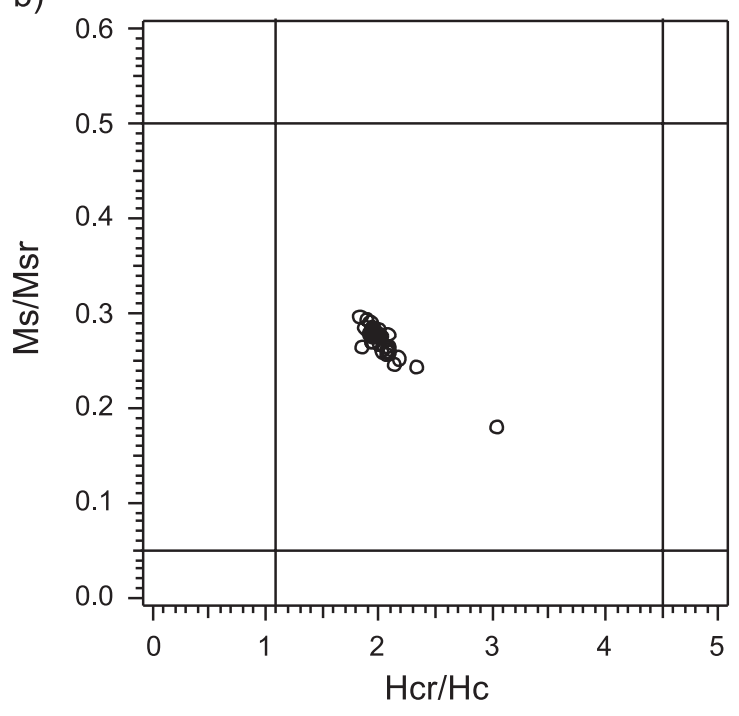

Fig. 3. Typical hysteresis loops (a) and hysteresis parameters (b) for Site 1218. Samples plotted in (b) are the same 34 samples used in IRM analysis. 

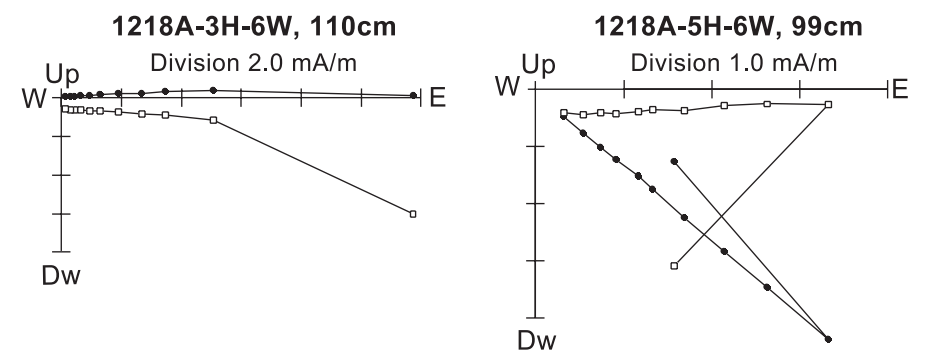

1218A-9H-7A, $13 \mathrm{~cm}$

Division: $0.2 \mathrm{~mA} / \mathrm{m}$
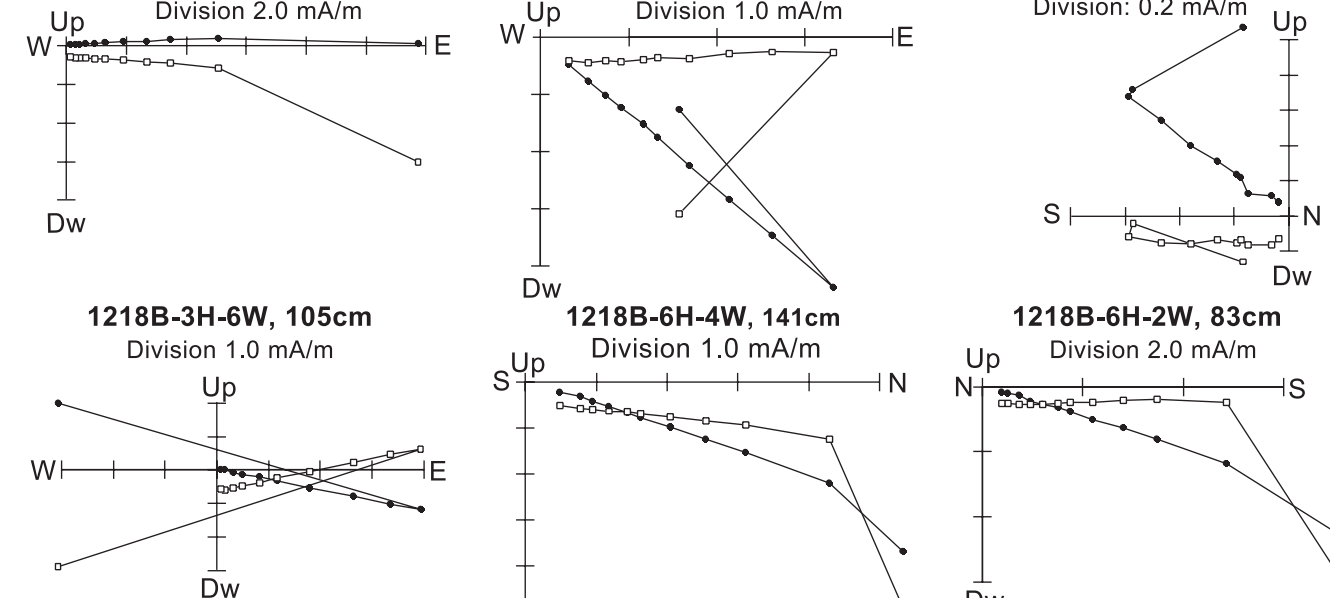

1218B-7H-7W, $35 \mathrm{~cm}$

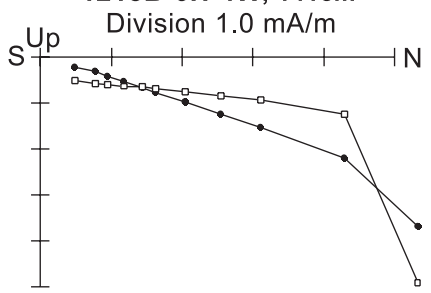

1218B-6H-2W, $83 \mathrm{~cm}$
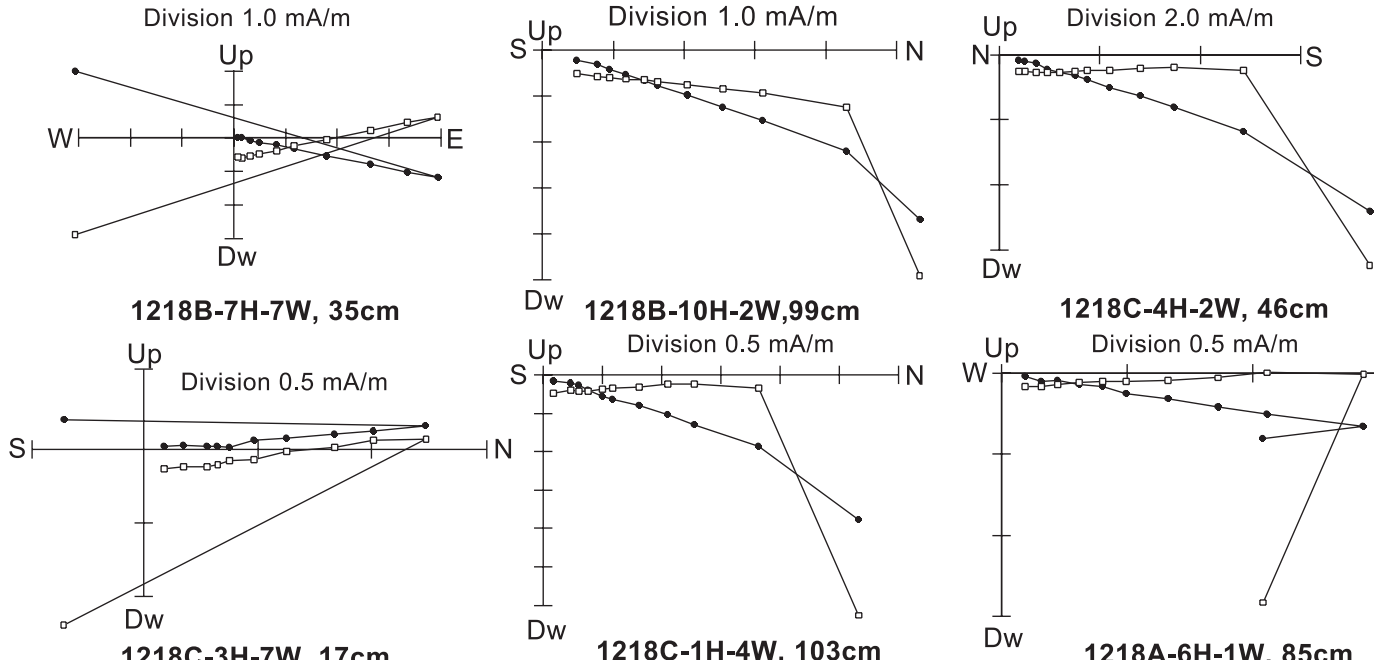

Dw 1218B-10H-2W,99cm

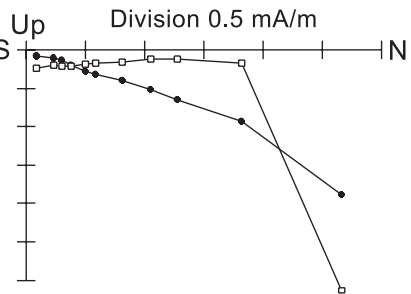

1218C-3H-7W, $17 \mathrm{~cm}$

$1218 \mathrm{C}-1 \mathrm{H}-4 \mathrm{~W}, 103 \mathrm{~cm}$

Division $0.5 \mathrm{~mA} / \mathrm{m}$

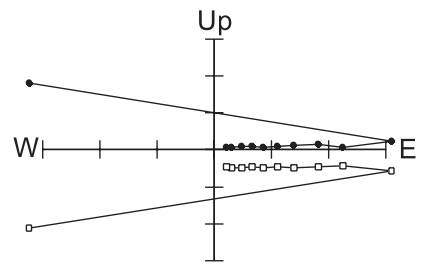

Division $1.0 \mathrm{~mA} / \mathrm{m}$

Dw
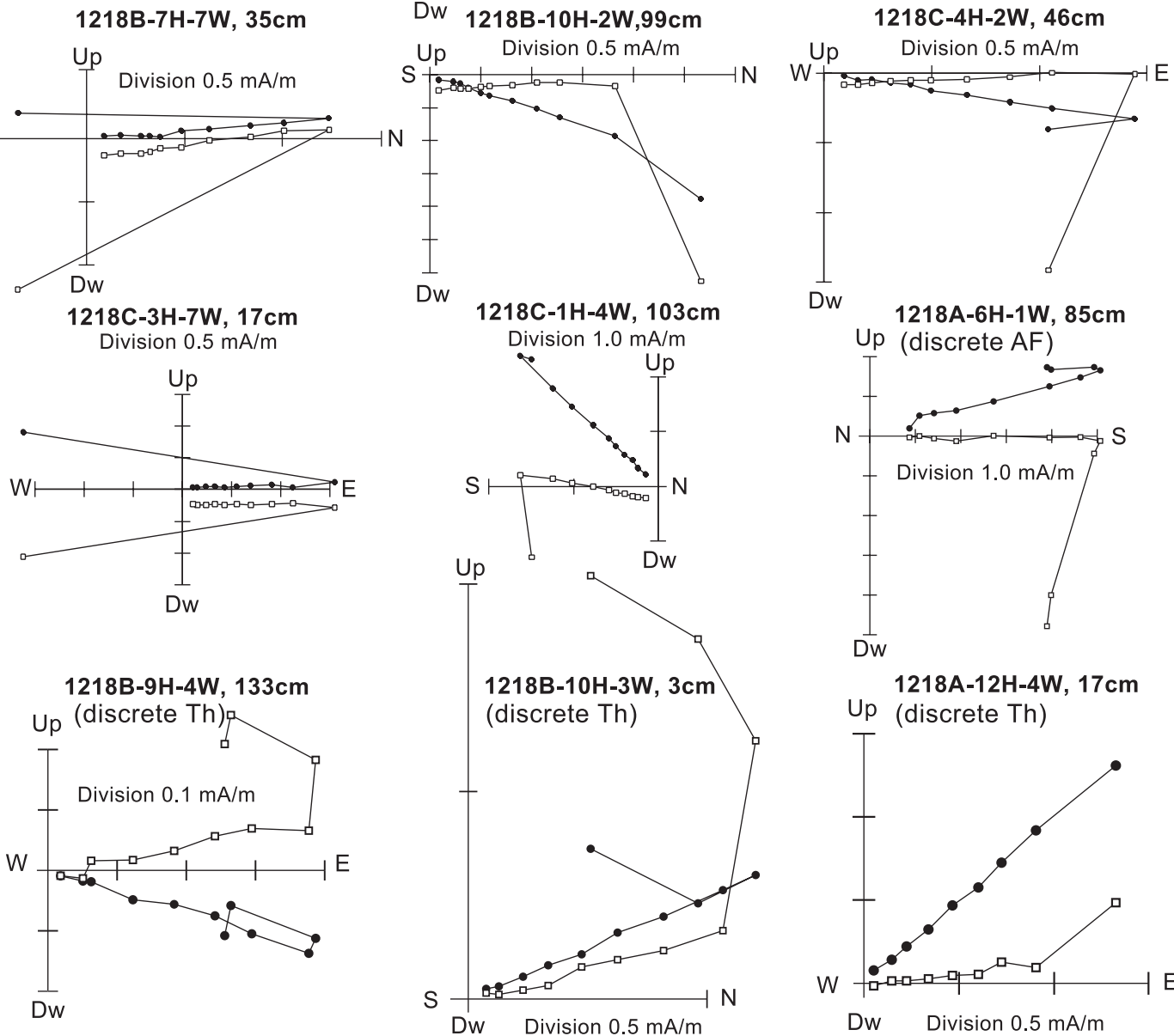

Dw

1218A-6H-1W, 85cm Up (discrete AF)

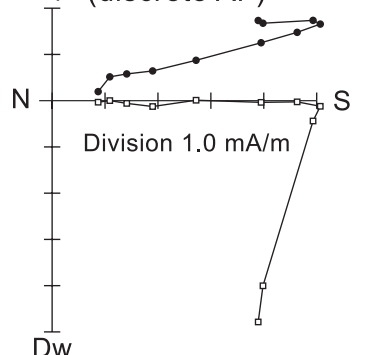

1218A-12H-4W, $17 \mathrm{~cm}$

Up (discrete Th)

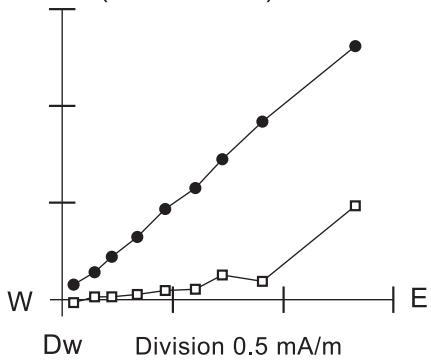

Fig. 4. Typical Zijderveld plots for Site 1218, open and closed symbols represent the vertical and horizontal projection respectively. Samples declination is not oriented to the geographic North. The AF demagnetization fields are NRM, 10, 20, 25, 30, 35, 40, 45, 50, 60, 80 mT; thermal demagnetization steps (lowest row of three plots) are NRM, 100, 200, 300, 350, 400, 450, 500, 525, 550, $575^{\circ} \mathrm{C}$. 
parameters are well grouped in the pseudo singledomain field with a $M_{\mathrm{r}} / M_{\mathrm{S}}$ value of about 0.3 . This suggests a uniform grain size of the magnetite particles along the sediment column with a little apparent influence of differing lithologies.

\section{Paleomagnetic directions}

\subsection{Core orientation}

Because of the nearly equatorial present-day $\left(8^{\circ} 53^{\prime} \mathrm{N}\right)$ and expected paleolatitude of Site 1218 , azimuthal orientation of cores is of the utmost importance for interpretation of magnetic polarity. The APC cores collected from Site 1218 were oriented using the "tensor tool". For technical reasons, as is standard practice, the cores from Holes A and B were oriented starting from core number 3 . Since the first two cores, constituting approximately $17 \mathrm{~m}$ of sediments, could not be azimuthally oriented, they were not sampled.

The tensor tool provided a good first-order orientation for most of the cores with errors up to about $\pm 30^{\circ}$ that, although large, enabled the polarity of magnetization to be established. During the shipboard measurements, to compensate for the poor precision of the azimuthal orientation, we adjusted the mean declination of some cores, computed using Fisher statistics [10], to the geographic north/south by a small rotation (of the order of the tensor tool precision) about a vertical axis. Small differences of about $10^{\circ}$ between mean declination and the north/ south were ignored. In all cases, the overlap among Holes 1218A, 1218B, and 1218C allowed the results to be cross-checked for consistency and no ambiguity resulted.

\subsection{ChRM directions}

The component magnetization directions were calculated by principal component analysis [11] using from 6 to 8 demagnetization steps in the 20-60 mT peak field range. The quality of the measurements and the line fitting was checked by visual inspection of the orthogonal vector plots [12] and was quantified using the maximum angular deviation (MAD). The average value of MAD in the Miocene samples is $5.5^{\circ}$ and

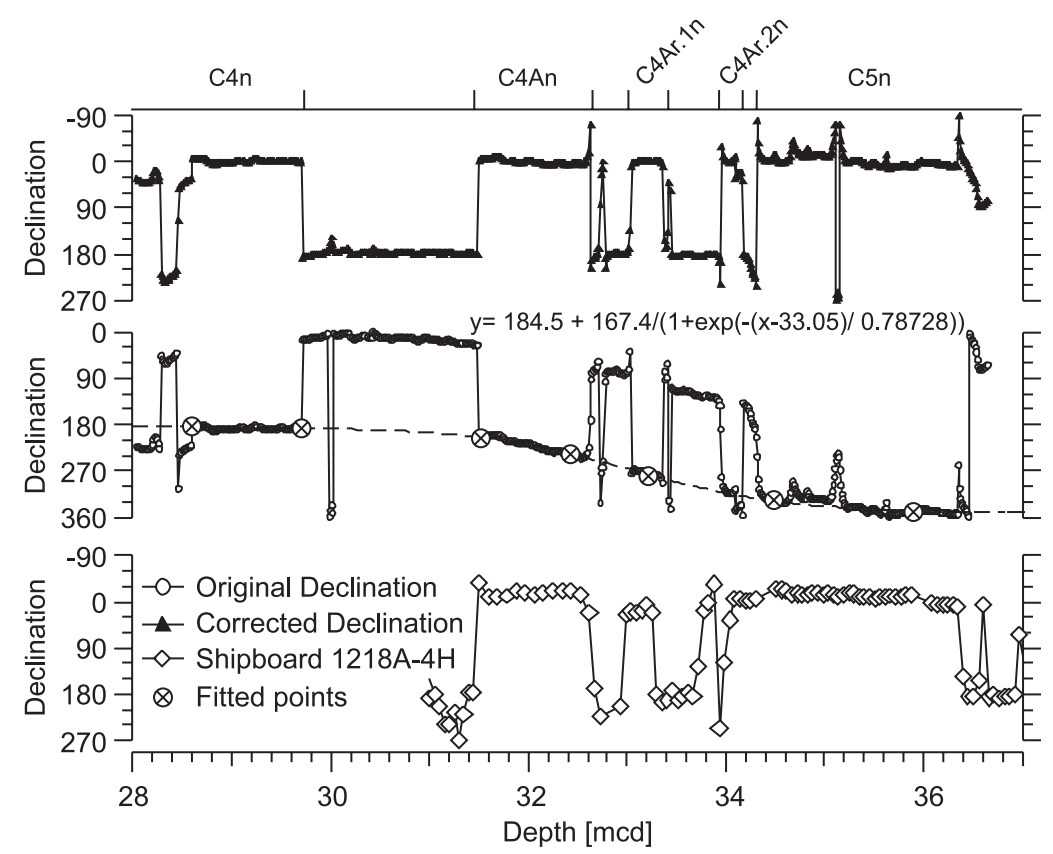

Fig. 5. Correction of ChRM declination in core 1218B-4 H. Crossed open symbols are the data point selected to fit a sigmoid function that approximate the declination bias along the core (thick line). The values of declination after correction, agree well with the shipboard data from parallel core $1218 \mathrm{~A}-4 \mathrm{H}$ plotted in the lower panel with open diamonds. 
Table 1

Mean directions and Fisher statistics for normal and reversed samples, the calculation does not include data from core $1218 \mathrm{~B}-4 \mathrm{H}$ because of the problems discussed in the text

\begin{tabular}{lrrrlll}
\hline & \multicolumn{1}{l}{ Dec } & \multicolumn{1}{l}{ Inc } & $\alpha_{95}$ & $k$ & $\mathrm{R}$ & $\mathrm{N}$ \\
\hline Normal & $\mathbf{3 5 9 . 8}$ & $\mathbf{0 . 9}$ & $\mathbf{0 . 6}$ & $\mathbf{1 9 . 2 1}$ & $\mathbf{3 0 3 3 . 4 9}$ & $\mathbf{3 2 0 0}$ \\
Reverse & $\mathbf{1 8 1 . 6}$ & $-\mathbf{1 2 . 2}$ & $\mathbf{0 . 5}$ & $\mathbf{1 8 . 9 7}$ & $\mathbf{4 2 6 7 . 6 2}$ & $\mathbf{4 5 0 5}$ \\
Normal & 0.2 & -0.2 & 0.6 & 15.18 & 3033.20 & 3536 \\
Reverse & 181.2 & -12.9 & 0.5 & 15.12 & 4434.12 & 4748 \\
\hline
\end{tabular}

Mean from samples with MAD angle $<15^{\circ}$, first 2 lines in boldface. The mean directions are closely antipodal but do not pass the reversal test.

only a small percentage of samples (6.5\%) have a MAD value larger than $15^{\circ}$.

The AF demagnetization technique was effective to demagnetize NRM in the measured samples. On average, more than $90 \%(93.5 \%)$ of the NRM, calculated using the scalar sum of the vector differences [13], was removed at peak fields of $80 \mathrm{mT}$. AF demagnetization was effective also in the interval used to calculate the ChRM; $71 \%$ of the NRM that remained after demagnetization at peak fields of 20 $\mathrm{mT}$ AF demagnetization was removed at the field of $60 \mathrm{mT}$.

Typical orthogonal vector plots for the Miocene section of Site 1218 are illustrated in Fig. 4. All the samples show a soft (viscous) component, which is generally removed after AF demagnetization at 10-20 $\mathrm{mT}$, followed by a linear vector decay more or less towards the origin to a maximum peak field of $80-100$ $\mathrm{mT}$ that is interpreted as the ChRM. Most samples show a high coercivity component with a steep downward direction, which could not be removed at peak fields of 80 or $100 \mathrm{mT}$. This component is of variable intensity, particularly pronounced in sample 1218A-9H-7, and can be easily seen in the Zijderveld plots in Fig. 4. Because of its steep inclination, it does not seem to be related to the primary magnetization, and is not observed in thermally demagnetized or $\mathrm{AF}$ demagnetized discrete samples (i.e., samples 1218B$9 \mathrm{H}-7 \mathrm{~W}, 1218 \mathrm{~A}-12 \mathrm{H}-4 \mathrm{~W}$ and $1218 \mathrm{~B}-10 \mathrm{H}-3 \mathrm{~W}$ in Fig. 4). The origin of the high coercivity component remains unknown but is either drilling induced or an ARM systematically induced during AF demagnetization. To avoid any contamination of the ChRM by this hard downward component, the best-fit line defining the characteristic magnetization component was always calculated without anchoring to the origin.
Except for the absence of the downward vertical component, the Zijderveld plots and ChRM directions obtained from thermal demagnetization and $\mathrm{AF}$ demagnetization of discrete samples are very similar to that obtained with AF demagnetization in u-channel samples (three plots at base of Fig. 4).

Site 1218 yields a coherent record of paleomagnetic directions apart from one interval, in core $1218 \mathrm{~B}-4 \mathrm{H}$, that showed anomalous directions probably because of disturbance during drilling, core transport or sampling. Although the NRM shows
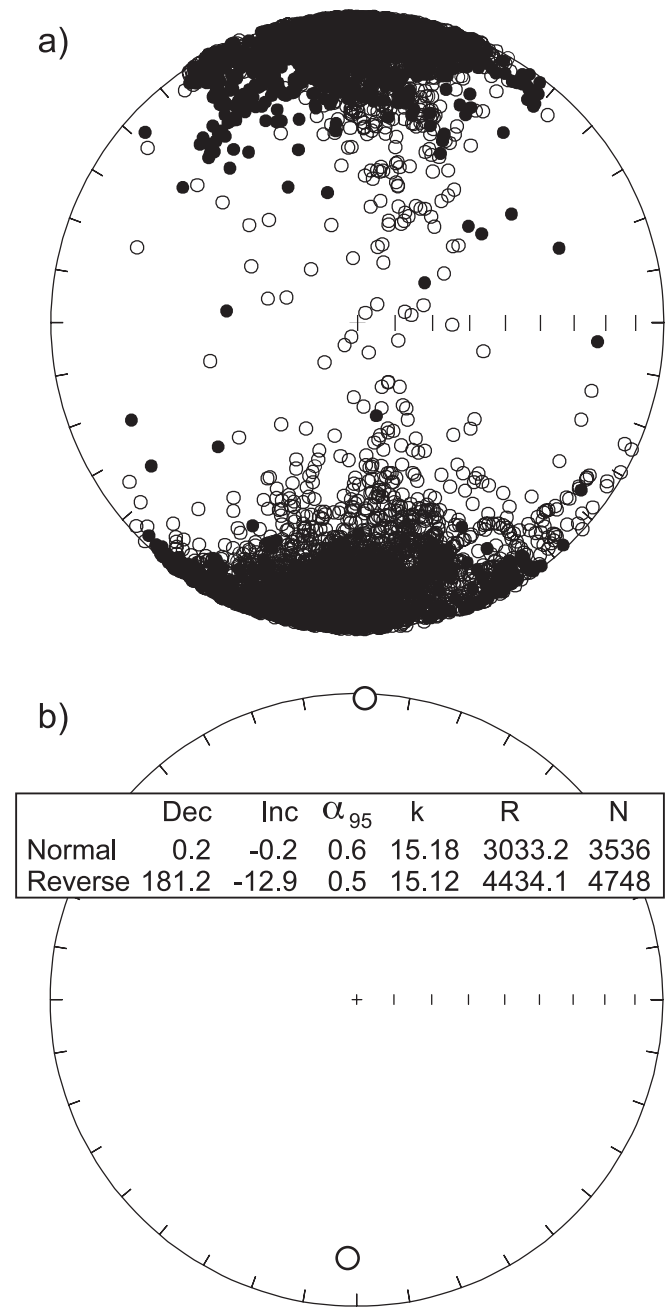

Fig. 6. (a) Equal area projection of the ChRM directions for the Miocene section of Site 1218. Directions from core 1218B-4H are not included. (b) Mean directions for normal and reversed directions, the confidence circle $\alpha_{95}$ is smaller than the plot symbols. 


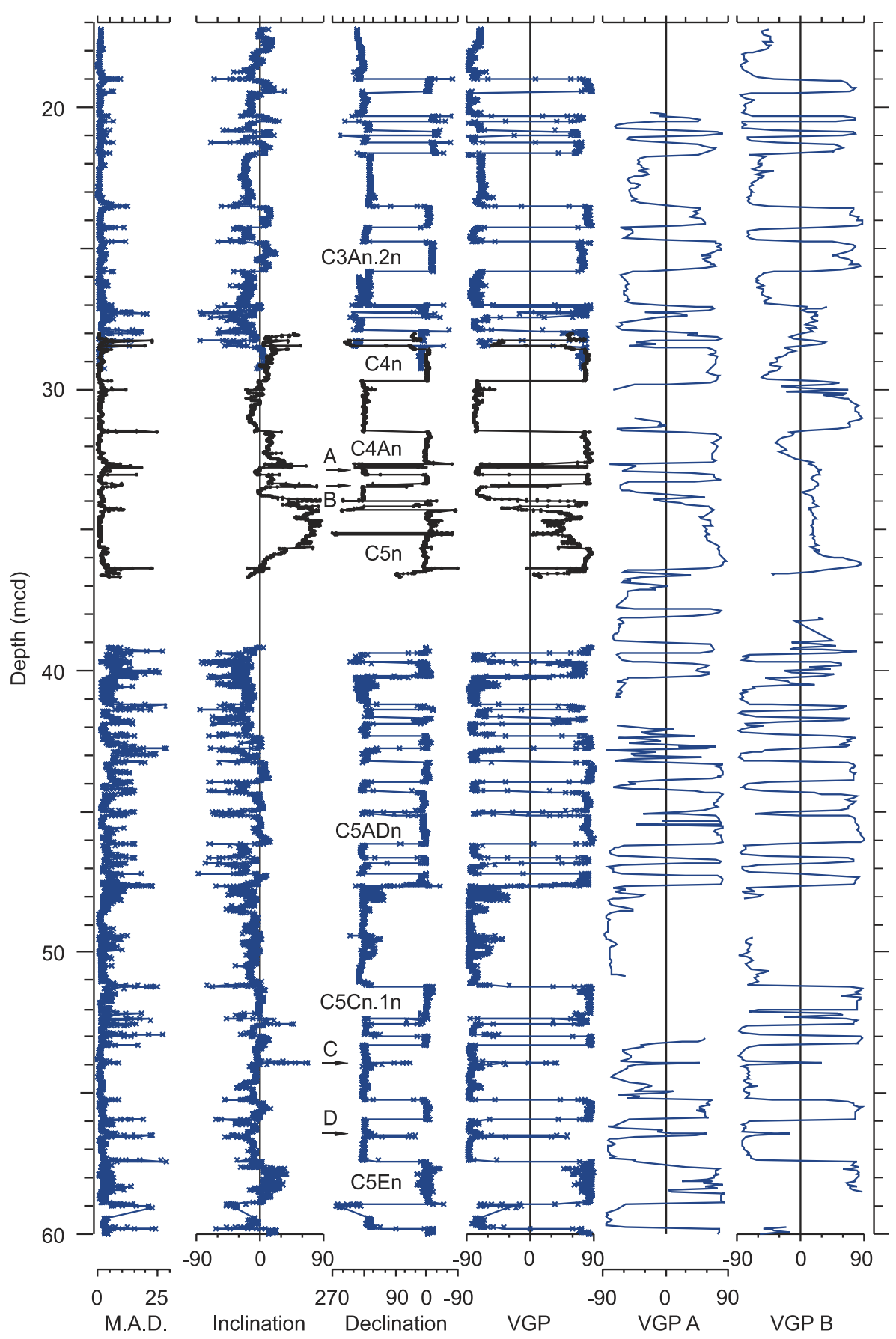

Fig. 7. Paleomagnetic directions, VGP latitude and MAD for u-channel samples and VGP latitude from shipboard measurements in upper half of the section at Site 1218. Black symbols (from $\sim 27$ to $\sim 38 \mathrm{mcd}$ ) are from core 1218B-4H. Letters A to D indicate short polarity events. 
well-defined vectors with low MAD values, the ChRM declinations appear to be increasingly rotated from the bottom to the top of the core. These directions are clearly inconsistent with those expected and with shipboard results from correlative core 1218A-4H (Fig. 5). Unfortunately, the correlative core in Hole 1218A (1218A-4H), which was not disturbed and gave good shipboard results, could not be sampled because it is part of the permanent archive. Instead of discarding the interval in core $1218 \mathrm{~B}-4 \mathrm{H}$ and leaving a large gap of about $8 \mathrm{~m}$ in the record, we have corrected the directions using the method described below. Results were validated by comparison with the shipboard measurements (blanket demagnetization at $20 \mathrm{mT}$ ) from core 1218A-4H.
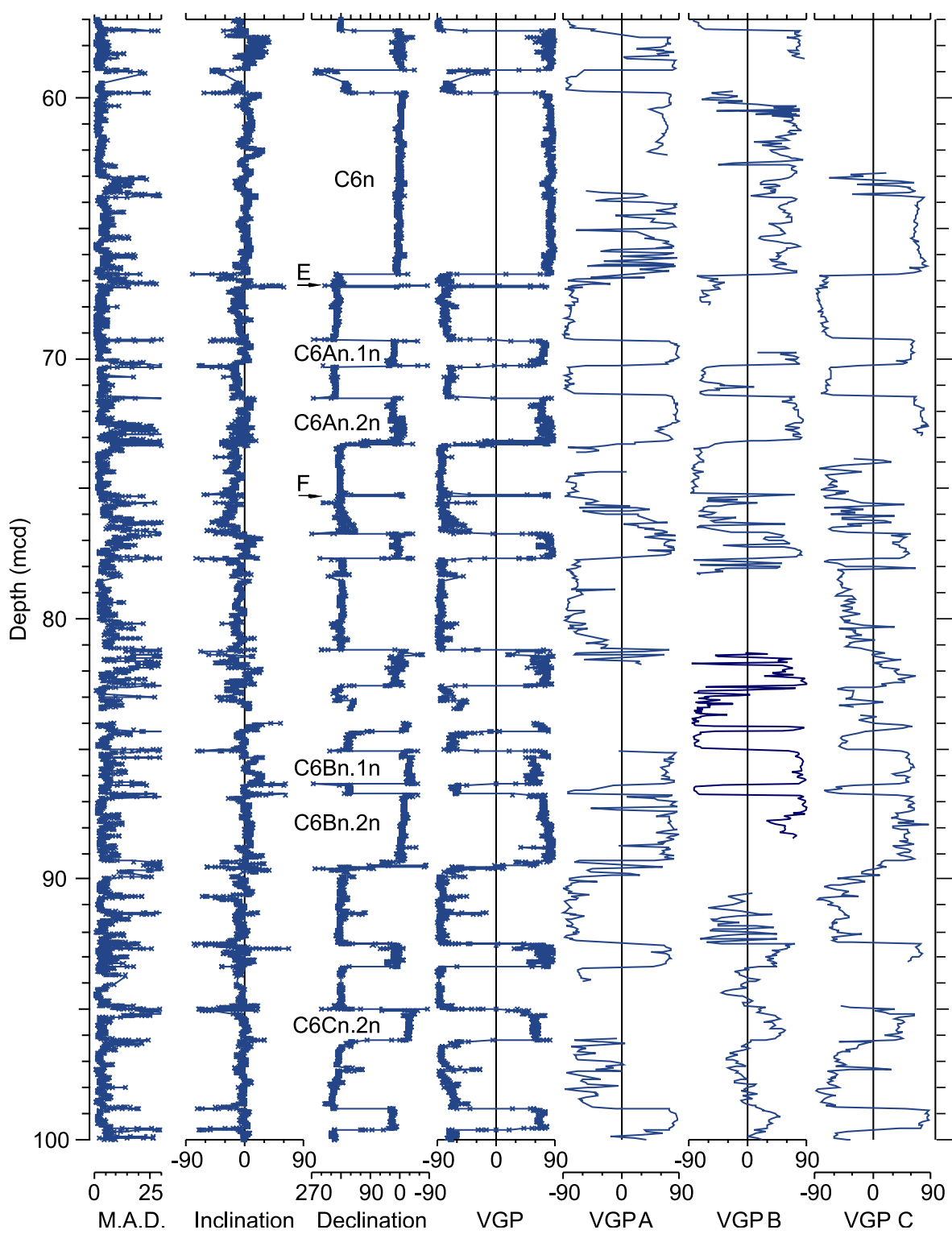

Fig. 8. Paleomagnetic directions, VGP latitude and MAD for u-channel samples and VGP latitude from shipboard measurements in bottom half of the section at Site 1218. Letters $\mathrm{E}$ and $\mathrm{F}$ indicate short polarity events. 
To correct the ChRM declinations for core 1218B$4 \mathrm{H}$, we selected a small number of declination points that we believed represents the same (normal) polarity. We then fit these points with a sigmoidal function and we rotated all declinations by an angle equal to the difference between the fitted function and the North. The process is illustrated in Fig. 5. The corrected ChRM declinations are in good agreement with shipboard results from parallel core $1218 \mathrm{~A}-4 \mathrm{H}$. We have plotted the modified data in subsequent figures using a different symbol to clearly distinguish them from the rest. An additional problem that we did not correct is the abnormally high inclinations of sections $1218 \mathrm{~B}-4 \mathrm{H}-4$ and $1218 \mathrm{~B}-4 \mathrm{H}-5$ in the $34-36$ mcd interval.

Mean directions computed with Fisher statistics separately for the normal and reverse polarity samples are shown in Table 1 and in Fig. 6. The data set in Fig. 6 does not include directions from core 1218B-4H and the discrete samples; note that the re-orientation of cores does not induce biases in the reversal test because both normal and reverse components are rotated by the same angle. Although nearly antipodal, the normal and reverse directions are significantly different at the $95 \%$ confidence level because the very small $\alpha_{95}$ confidence circles do not intersect. For this reason, the data do not pass the reversal test. Failure of reversal test is mostly due to the difference between reverse and normal polarity inclinations, the former being $\sim 10^{\circ}$ steeper than the later. This could be a consequence of the influence of the high coercivity component mentioned above or a characteristic of the geomagnetic field (see discussion below).

\section{Results and discussion}

\subsection{Magnetostratigraphy}

ChRM directions (declinations and inclinations), VGP latitude, MAD angles from u-channel measurements and VGP latitude from shipboard measurements are plotted versus med in Figs. 7 and 8 . Paleomagnetic polarity is interpreted using the VGP latitude, which combines information from declination and inclination. Pleistocene magnetostratigraphy at Site 1218 is inferred from shipboard measurements of declination in $1218 \mathrm{~A}-1 \mathrm{H}$ that, even without orientation, can be easily interpreted for magnetic polarity to about $2 \mathrm{Ma}$ (Fig. 9). Therefore, the topmost $8 \mathrm{~m}$ of sediments represent the complete Pleistocene. Shipboard data from subsequent core 1218A-2H do not have a straightforward interpretation of the polarity sequence. The upper sediments at Site 1218 were deposited well below the carbonate compensation depth and calcareous fossils are lacking from the seafloor to Sample 1218A-4H-6, $50 \mathrm{~cm}$, because of calcite dissolution [2]. Nonetheless, based on the magnetostratigraphy corroborated by limited biostratigraphic data, we are confident that the uppermost part of the measured section comprises Pliocene polarity zones correlative to Chron C2Ar. Magnetostratigraphy, in fact, provides the only useful age control in this part of the core and, based on magnetostratigraphic results, the Miocene/Pliocene boundary can be assigned to the depth of about $23.5 \mathrm{mcd}$ near the end of chron $\mathrm{C} 3 \mathrm{r}$.

The Miocene magnetostratigraphy of Site 1218 is summarized in Fig. 10 that merges VGP latitude from u-channel, discrete samples and shipboard data to cover the sampling gap. Samples with MAD values larger than $15^{\circ}$ (marked with an open symbol) tend to

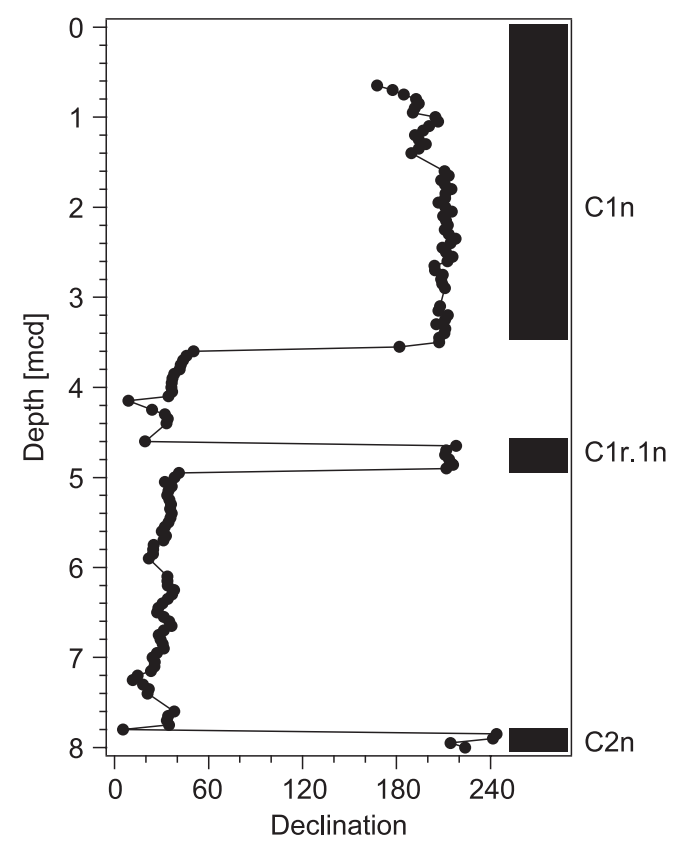

Fig. 9. Declinations from shipboard measurements in core 1218A1H. Despite the lack of azimuthal orientation the Pleistocene reversal sequence can be easily recognized. 


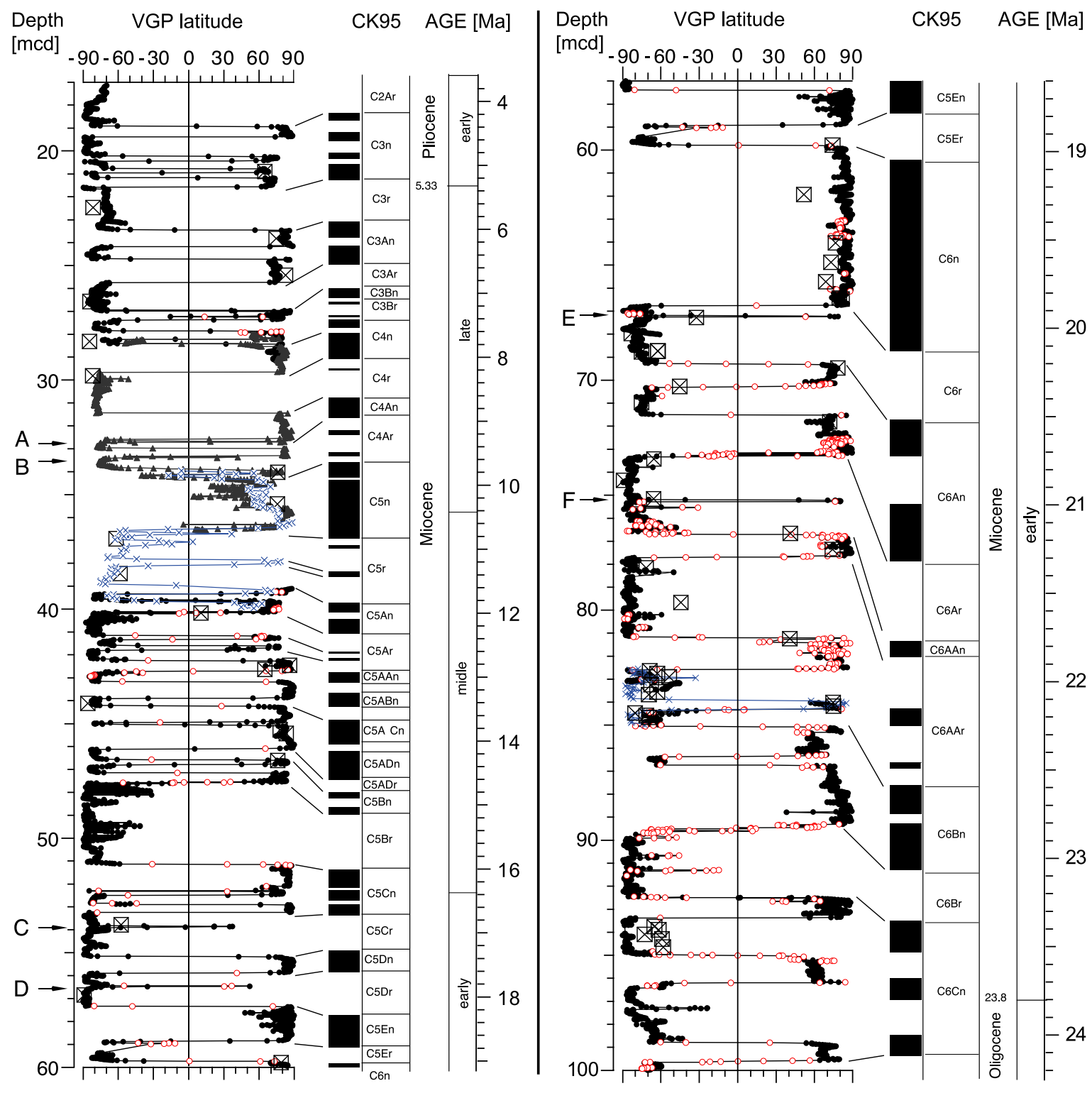

S Samples with MAD $>15 \multimap$ Core 1218B-4H $\times$ Shipboard data $\otimes$ Discrete Samples $\rightarrow$ U-channel samples

Fig. 10. VGP latitude from component magnetization directions from u-channel samples from Site 1218, together with shipboard data (crosses), discrete sample data (crossed squares) and correlation to the geomagnetic polarity timescale of Cande and Kent (1995). Letters A to F indicate short polarity events.

coincide mostly with polarity transitions, probably as a consequence of the low NRM intensity generally measured in these intervals. We believe we have confidently identified chrons $\mathrm{C} 4 \mathrm{r}$ to $\mathrm{C} 5 \mathrm{n}$ in core $1218 \mathrm{~B}-4 \mathrm{H}$ and the overall interpretation is supported by the shipboard results from correlative core 1218A-
$4 \mathrm{H}$. The VGP record is relatively poor in sections $1218 \mathrm{~B}-4 \mathrm{H}-5$ and $1218 \mathrm{~B}-4 \mathrm{H}-6$ from about 34 to about 36 mcd corresponding to chron $\mathrm{C} 5 \mathrm{n}$ because of anomalously high inclinations, we do not attempt to interpret the small-scale features in this interval. Otherwise, the high resolution of $\mathrm{u}$-channel measure- 
ments allowed us to resolve almost all the Miocene polarity chrons in the standard GPTS of Cande and Kent [14] (hereafter CK95) geomagnetic polarity time scale in spite of the low sedimentation rate of the brown clays sedimentary unit. The only exceptions are chrons $\mathrm{C} 3 \mathrm{Br} .2 \mathrm{n}$ and $\mathrm{C} 4 \mathrm{r} .1 \mathrm{n}$ that have durations of about $30 \mathrm{kyr}[14,15]$ and were not detected in the original data. Evidence for these short chrons is observed in the deconvolved data (Fig. 11) that show fluctuations of the VGP latitude that can be interpreted as chrons $\mathrm{C} 3 \mathrm{Br} .2 \mathrm{n}$ and $\mathrm{C} 4 \mathrm{r} .1 \mathrm{n}$.

Data deconvolution was attempted to improve resolution in the low-sedimentation-rate Miocene sediments by removing the smoothing effect created by the relatively large (about $4 \mathrm{~cm}$ ) response function of the magnetometer pick-up coils. We used the method described by Oda and Shibuya [7] using Akaike's Bayesian Information Criterion (ABIC) minimization for application to measurements from the shipboard pass-through magnetometer. The procedure has been modified for the University of Florida u-channel magnetometer by Guyodo et al. [6] and was applied to all core sections from chron C3An.1r to chron C5n (about 26 to $34 \mathrm{mcd}$ ). This part of the sedimentary record contains several thin magnetozones that were barely resolved in the original measurements and some expected subchrons (e.g., C3Bn.2r and C4r.1n) that were not resolved at all. The average sedimentation rate in this part of the core is low, about $2.1 \mathrm{~m} / \mathrm{Myr}$ calculated between the end of chron $\mathrm{C} 3 \mathrm{Bn}$ and the end of C4n.2n, and $2.4 \mathrm{~m} / \mathrm{My}$ in chron $\mathrm{C} 4 \mathrm{r}$ according to the GPTS of Shackleton et al. [15] and CK95 [14]. This translates into an expected thickness of polarity zones correlative to chrons $\mathrm{C} 3 \mathrm{Br}, \mathrm{C} 3 \mathrm{Bn} .2 \mathrm{r}$ and $\mathrm{C} 4 \mathrm{r} .1 \mathrm{n}$ of about 12,6 and $7 \mathrm{~cm}$, respectively.

Deconvolved directions are compared with original data in Fig. 11. There are no large changes in MAD values between the two sets of data and the most significant changes seem to be in inclination. Data deconvolution appears to improve the spatial reso-
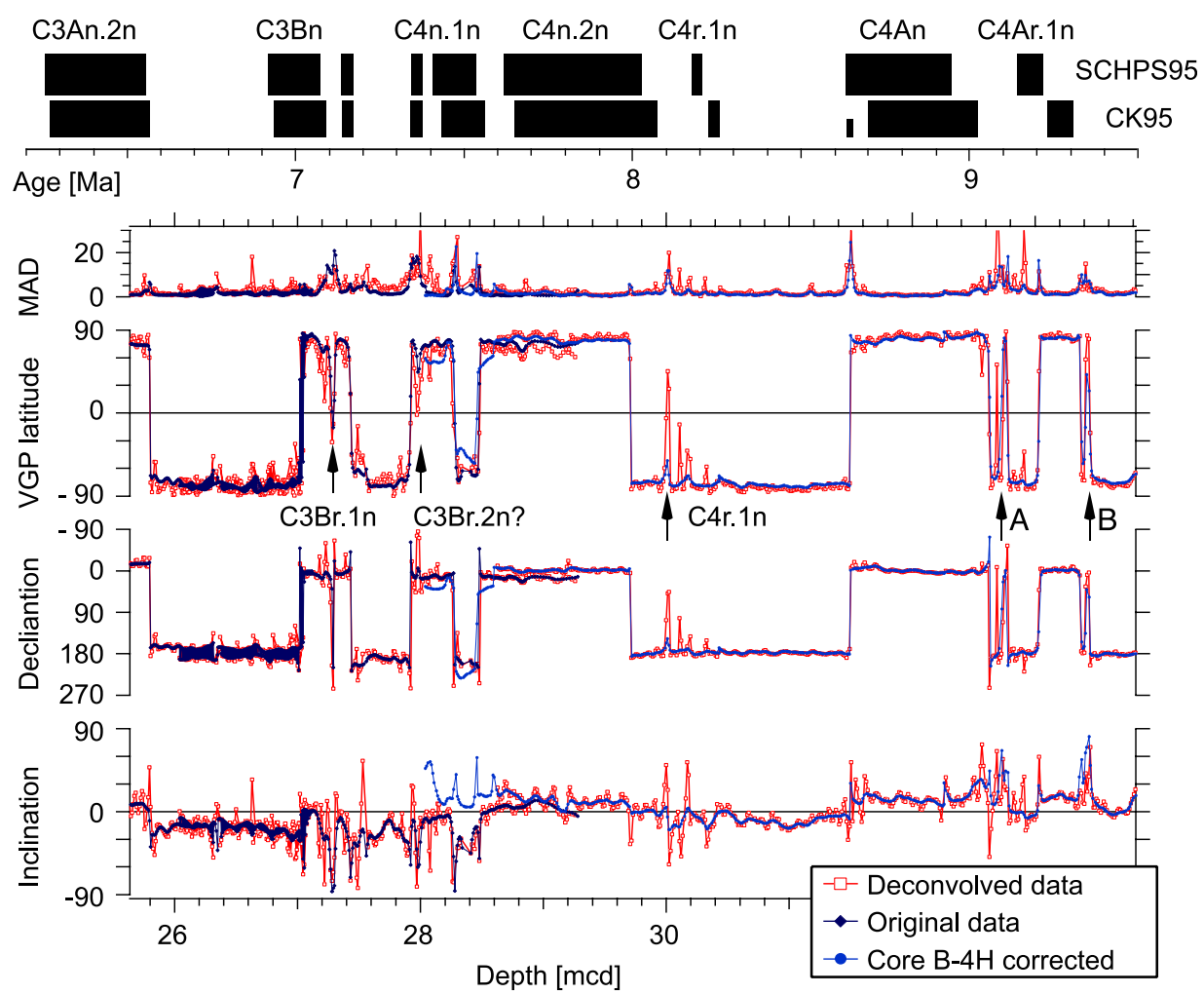

Fig. 11. Result of data deconvolution in interval from chron C3An.1r to chron C4n.2n (Upper Miocene). Deconvolved data are shown as ChRM direction, MAD and VGP latitude with open symbols, and compared with original data plotted with filled symbols. Letters A and B indicate short polarity events. 
lution by emphasizing the variation of VGP latitude at $\mathrm{C} 3 \mathrm{Br}$ and creating a pronounced variation of the VGP latitude at 27.97 med that can be interpreted as C3Bn.2r. The short variation of the VGP latitude up to $45^{\circ} \mathrm{N}$ in chron $\mathrm{C} 4 \mathrm{r}$ at $30.01 \mathrm{mcd}$ can also be interpreted as evidence of chron C4r.1n.

The results of data deconvolution are useful for detecting short polarity zones in this section even though the improvement is not substantial, possibly due to amplification of the background noise using this technique. Nevertheless, these observations can be used to place some limits on the resolution of $\mathrm{u}$ channel measurements that can be expected from the sediments at this site. Based on the examples of chrons $\mathrm{C} 3 \mathrm{Br}, \mathrm{C} 3 \mathrm{Bn} .2 \mathrm{r}$ and $\mathrm{C} 4 \mathrm{r} .1 \mathrm{n}$, we conclude that polarity chrons with duration equivalent to the deposition of a 5-cm stratigraphic interval may not be recorded, whereas polarity chrons with duration equivalent to a $10-\mathrm{cm}$ or thicker stratigraphic interval would most probably be recorded.

The transition from the upper brown clay sedimentary unit to the underlying carbonate sediments is marked by an increased sedimentation rate (Fig. 12) and an increased abundance of carbonate due to the high productivity associated with equatorial upwelling [2]. This change occurs rather sharply at about $80 \mathrm{mcd}$

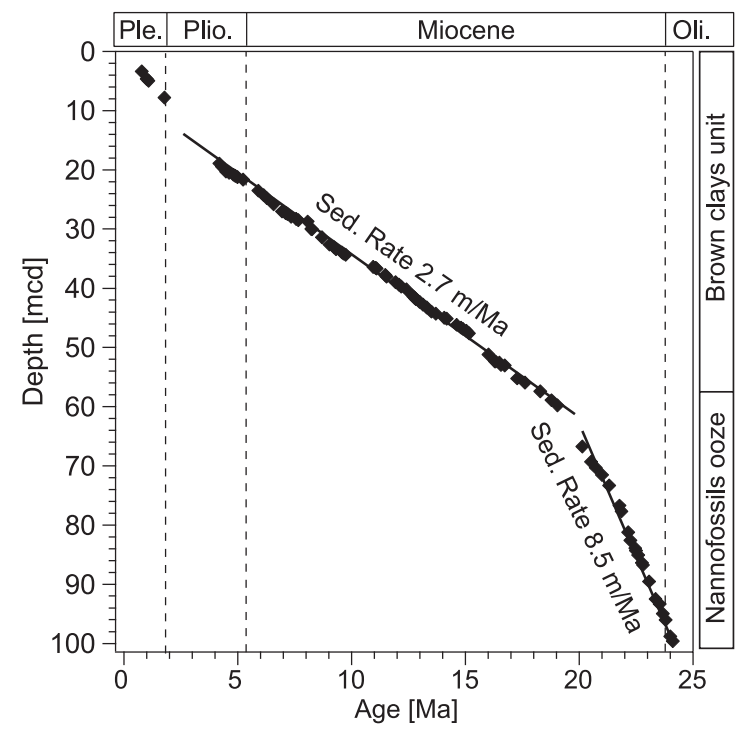

Fig. 12. Age (GPTS of CK95) versus core depth and average sedimentation rates for early Miocene nannofossils ooze sedimentary unit and the upper Miocene to Pleistocene brown clays unit. Pleistocene polarity chrons are from core $1218 \mathrm{~A}-1 \mathrm{H}$.
(Fig. 12). Below this depth the average sedimentation rate of about $8.5 \mathrm{~m} / \mathrm{Myr}$ allows an increase in magnetostratigraphic resolution of about 3 -fold compared to late Miocene. The Oligocene/Miocene boundary, which is set at the onset of chron C6Cn.2n [16], occurs at about 96 med in Site 1218.

Each recognized polarity chron is listed in Table 2 using the standard ODP notation (Site-Hole-Core and position from top of the core) to identify its position in the core. A few very short subchrons or excursions that are not reported in the CK95 [14] have been identified at Site 1218 and are marked in Table 3 with letters A to F. Their durations were estimated from the GPTS and vary from about 8 to $23 \mathrm{kyr}$ (Table 3). We note that event B in chron C4Ar.1r and event D in chron C5Dr correlate well with similar short polarity subchrons found at ODP Site 1090 [17] and DSDP Site 608 [18]. The significance of these features as possible short polarity intervals or excursions of the geomagnetic field remains unclear (e.g., see discussion in [18]) and will not be discussed further in this paper.

\subsection{Comparison with shipboard results}

The u-channel based magnetostratigraphy shows generally good agreement with the shipboard results [2], which are based on blanket demagnetization at peak fields of $20 \mathrm{mT}$ and 5 -cm measurement spacing. The new data take advantage of higher sampling resolution and stepwise demagnetization. The higher spatial resolution of u-channel data results from the sharper response function of the u-channel passthrough magnetometer compared to the shipboard pass-through magnetometer that was designed for the whole and half cores.

Polarity transitions are sharp in u-channel measurements and occur within 1-3 cm stratigraphic distances compared to the $10-15 \mathrm{~cm}$ for shipboard data. This is particularly important for definition of polarity zones in the low sedimentation rate sediments of the lower and middle Miocene units. Polarity zones correlative to polarity chrons $\mathrm{C} 3 \mathrm{n} .1 \mathrm{n}$ to $\mathrm{C} 3 \mathrm{n} .4 \mathrm{n}$ and $\mathrm{C} 5 \mathrm{Ar} .1 \mathrm{n}$, C5An.2n and $\mathrm{C} 5 \mathrm{ACr}$ were already identified in shipboard data, but their relative thicknesses are much better defined from u-channel measurements. Polarity chrons $\mathrm{C} 3 \mathrm{Br}$ and $\mathrm{C} 5 \mathrm{Cn}$.1r were only identified in uchannel measurements. The interval between 28 and 36 mcd recording polarity chrons $\mathrm{C} 4 \mathrm{n}$ to $\mathrm{C} 5 \mathrm{n}$ was 
Table 2

Magnetic polarity chrons identified in the Miocene section of Site 1218

\begin{tabular}{|c|c|c|c|c|}
\hline Chron & $\begin{array}{l}\text { Top } \\
\text { (section, cm) }\end{array}$ & $\begin{array}{l}\text { Bottom } \\
\text { (section, cm) }\end{array}$ & $\begin{array}{l}\text { Depth } \\
\text { (mcd) }\end{array}$ & Note \\
\hline $\mathrm{C} 1 \mathrm{n}$ & $1218 \mathrm{~A}-1 \mathrm{H}-1,0.0$ & $1218 \mathrm{~A}-1 \mathrm{H}-3,55.0$ & $0.00-3.35$ & Shipboard data \\
\hline C1r.1n & $1218 \mathrm{~A}-1 \mathrm{H}-4,10.0$ & $1218 \mathrm{~A}-1 \mathrm{H}-4,40.0$ & $4.60-4.90$ & Shipboard data \\
\hline C1r.2n & 1218A-1H-6, 25.0 & & $7.90-$ & Shipboard data \\
\hline C $3 n .1 n$ & $1218 \mathrm{~B}-3 \mathrm{H}-2,26.0$ & 1218B-3H-2, 72.0 & $18.94-19.44$ & \\
\hline$C 3 n .2 n$ & 1218B-3H-3, 7.0 & $1218 \mathrm{~B}-3 \mathrm{H}-3,28.0$ & $20.29-20.50$ & \\
\hline C $3 n .3 n$ & 1218B-3H-3, 61.0 & 1218B-3H-3, 79.0 & $20.83-21.01$ & \\
\hline $\mathrm{C} 3 \mathrm{n} .4 \mathrm{n}$ & 1218B-3H-3, 101.0 & 1218B-3H-3, 142.0 & $21.23-21.64$ & \\
\hline C3An.1n & 1218B-3H-5, 27.0 & $1218 \mathrm{~B}-3 \mathrm{H}-5,94.0$ & $23.50-24.24$ & \\
\hline C 3 An.2n & 1218B-3H-5, 144.0 & 1218B-3H-6, 95.0 & $24.77-25.80$ & \\
\hline \multirow[t]{2}{*}{$\mathrm{C} 3 \mathrm{Bn}$} & 1218A-3H-5, 98.0 & $1218 \mathrm{~A}-3 \mathrm{H}-5,123.0$ & $27.03-27.27$ & \\
\hline & 1218B-3H-7, 69.0 & & & \\
\hline $\mathrm{C} 3 \mathrm{Br} .1 \mathrm{n}$ & $1218 \mathrm{~A}-3 \mathrm{H}-5,127.0$ & $1218 \mathrm{~A}-3 \mathrm{H}-5,140.0$ & $27.31-27.44$ & \\
\hline $\mathrm{C} 3 \mathrm{Br} .2 \mathrm{n}$ & 1218A-3H-6, 38.0 & & $27.92-$ & Deconvolved data \\
\hline \multirow[t]{2}{*}{ C4n.1n } & & 1218A-3H-6, 74.0 & -28.28 & \\
\hline & & $1218 B-4 H-1,125.0$ & -28.29 & \\
\hline \multirow[t]{2}{*}{ C4n.2n } & $1218 \mathrm{~A}-3 \mathrm{H}-6,94.00$ & & $28.48-$ & \\
\hline & 1218B-4H-1, 139.0 & 1218B-4H-2, 91.0 & $28.47-28.72$ & \\
\hline C4r.1n & 1218B-4H-2, 115.0 & 1218B-4H-2, 118.0 & 29.99-30.02 & Deconvolved data \\
\hline C4An & 1218B-4H-3-88.0 & 1218B-4H-4-31.0 & $31.39-32.63$ & \\
\hline C4Ar.1n & 1218B-4H-4-63.0 & 1218B-4H-4-90.0 & 33.05-33.38 & \\
\hline C4Ar.2n & 1218B-4H-4-138.0 & 1218B-4H-5-6.0 & 33.95-34.17 & \\
\hline C5n.1n & 1218B-4H-5-20.0 & & $34.31-$ & \\
\hline C $5 n .2 n$ & & $1218 \mathrm{~A}-4 \mathrm{H}-4-40.0$ & -36.40 & Shipboard data \\
\hline C5r.1n & 1218A-4H-4-55.0 & $1218 \mathrm{~A}-4 \mathrm{H}-4-65.0$ & $36.55-36.65$ & Shipboard data \\
\hline C5r.2n & 1218A-4H-5, 20.0 & $1218 \mathrm{~A}-4 \mathrm{H}-5,45.0$ & $37.76-38.03$ & Shipboard data \\
\hline \multirow[t]{2}{*}{ C5An. $1 \mathrm{n}$} & $1218 \mathrm{~A}-4 \mathrm{H}-5,135.0$ & 1218A-4H-6, 20.0 & $38.97-39.39$ & Shipboard data \\
\hline & & 1218A-4H-6, 22.0 & -39.40 & \\
\hline \multirow[t]{2}{*}{ C5An.2n } & 1218A-4H-6, 52.0 & $1218 \mathrm{~A}-4 \mathrm{H}-6,104.0$ & $39.70-40.18$ & \\
\hline & $1218 \mathrm{~B}-5 \mathrm{H}-2,14.0$ & $1218 \mathrm{~B}-5 \mathrm{H}-2,65.0$ & & \\
\hline C5Ar.1n & 1218B-5H-3, 16.0 & 1218B-5H-3, 32.0 & $41.22-41.38$ & \\
\hline C5Ar.2n & $1218 \mathrm{~B}-5 \mathrm{H}-3,60.0$ & $1218 \mathrm{~B}-5 \mathrm{H}-3,79.0$ & $41.66-41.85$ & \\
\hline C5Aan & $1218 \mathrm{~B}-5 \mathrm{H}-3,124.0$ & 1218B-5H-4, 21.0 & $42.31-42.78$ & \\
\hline C5Abn & 1218B-5H-4, 67.0 & 1218B-5H-4, 139.0 & $43.23-43.95$ & \\
\hline C5can & 1218B-5H-5, 23.0 & 1218B-5H-5, 93.0 & $44.29-45.00$ & \\
\hline C5and & 1218B-5H-5, 105.0 & 1218B-5H-6, 50.0 & $45.12-46.17$ & \\
\hline C5Bn.1n & 1218B-5H-6, 94.0 & 1218B-5H-6, 113.0 & $46.64-46.85$ & \\
\hline \multirow[t]{2}{*}{ C $5 B n \cdot 2 n$} & 1218B-5H-6, 145.0 & $1218 \mathrm{~B}-5 \mathrm{H}-7,32.0$ & $47.20-47.62$ & \\
\hline & & 1218A-5H-5, 13.0 & & \\
\hline C5Cn.1n & 1218B-6H-2, 13.0 & $1218 \mathrm{~B}-6 \mathrm{H}-2,128.0$ & $51.19-52.34$ & \\
\hline $\mathrm{C} 5 \mathrm{Cn} .2 \mathrm{n}$ & 1218B-6H-2, 132.0 & 1218B-6H-2, 149.0 & $52.38-52.55$ & \\
\hline $\mathrm{C} 5 \mathrm{Cn} .3 \mathrm{n}$ & 1218B-6H-3, 39.0 & 1218B-6H-3, 73.0 & $52.96-53.03$ & \\
\hline C5Dn & 1218B-6H-4, 116.0 & 1218B-6H-5, 38.0 & $55.23-55.95$ & \\
\hline C5En & 1218B-6H-6, 34.0 & $1218 \mathrm{~A}-6 \mathrm{H}-4,137.0$ & $57.40-58.91$ & \\
\hline C6n & 1218B-7H-1, 41.0 & 1218B-7H-6, 71.0 & $59.78-66.75$ & \\
\hline C6An.1n & $1218 \mathrm{C}-1 \mathrm{H}-5,16.0$ & $1218 \mathrm{C}-1 \mathrm{H}-5,109.0$ & $69.29-70.28$ & \\
\hline \multirow[t]{2}{*}{ C6An.2n } & $1218 \mathrm{C}-1 \mathrm{H}-6,72.0$ & $1218 \mathrm{C}-1 \mathrm{H}-7,80.0$ & $71.51-73.31$ & \\
\hline & & 1218B-8H-3, 94.0 & & \\
\hline C6Aan & 1218B-8H-5, 147.0 & $1218 \mathrm{~B}-8 \mathrm{H}-7,3.0$ & $76.70-77.68$ & \\
\hline C6AAr.1n & $1218 \mathrm{C}-2 \mathrm{H}-5,91.0$ & $1218 \mathrm{C}-2 \mathrm{H}-6,87.0$ & $81.21-82.58$ & \\
\hline \multirow[t]{2}{*}{ C6AAr.2n } & 1218B-9H-4, 65.0 & 1218B-9H-4, 105.0 & 83.89-84.34 & Shipboard data \\
\hline & & $1218 \mathrm{C}-3 \mathrm{H}-1,58.0-60.0$ & -84.34 & \\
\hline
\end{tabular}


Table 2 (continued)

\begin{tabular}{|c|c|c|c|c|}
\hline Chron & $\begin{array}{l}\text { Top } \\
\text { (section, cm) }\end{array}$ & $\begin{array}{l}\text { Bottom } \\
\text { (section, cm) }\end{array}$ & $\begin{array}{l}\text { Depth } \\
\text { (mcd) }\end{array}$ & Note \\
\hline C6Bn.1n & $1218 \mathrm{C}-3 \mathrm{H}-1,126.0$ & $1218 \mathrm{C}-3 \mathrm{H}-2,100.0$ & $85.06-86.36$ & \\
\hline C6Bn.2n & $1218 \mathrm{C}-3 \mathrm{H}-2,138.0$ & $1218 \mathrm{C}-3 \mathrm{H}-4,115.0-119.0$ & $86.74-89.51$ & \\
\hline C6Cn.1n & $\begin{array}{l}1218 \mathrm{~B}-10 \mathrm{H}-2,18.0 \\
1218 \mathrm{C}-3 \mathrm{H}-6,143.0\end{array}$ & 1218B-10H-2, 115.0 & 92.49-93.37 & \\
\hline C6Cn.2n & $\begin{array}{l}\text { 1218C-4H-1, } 16.0 \\
1218 \mathrm{~A}-9 \mathrm{H}-7,77.0\end{array}$ & $1218 \mathrm{C}-4 \mathrm{H}-1,129.0$ & $94.99-96.02$ & \\
\hline C6Cn.3n & $1218 \mathrm{C}-4 \mathrm{H}-3,74.0$ & $1218 \mathrm{C}-4 \mathrm{H}-3,148.0$ & $98.80-99.62$ & \\
\hline
\end{tabular}

Depths are reported using the ODP convention (core-section interval) and as med. Boldface data are from core $1218 \mathrm{~B}-4 \mathrm{H}$.

poorly resolved in shipboard measurements. The magnetostratigraphy in this interval has been revised based on u-channel data. Polarity chrons C6AAn, C6AAr.1n and C6Cn.2n, which marks the Oligocene/ Miocene boundary, were not clearly defined in shipboard measurements probably due to the low NRM intensity, and are now precisely resolved in the uchannel data.

Several short polarity chrons are recorded in the uchannel measurements and there is a hint that some of these features, for example, $\mathrm{C}$ and $\mathrm{D}$ at 53.9 and 56.5 mcd, respectively, are also recorded in shipboard data in both Holes A and B. Overall, the u-channel data have greatly improved the fidelity of the magnetostratigraphy and the position of the polarity zone boundaries in the sedimentary column, which can generally be defined within $1-3 \mathrm{~cm}$.

\subsection{Paleolatitude and inclination asymmetry}

Paleomagnetic inclinations give valuable information on site paleolatitude. For a time-averaged geocentric axial dipole field, values of normal and reverse polarity inclination should be the same with opposite sign. However, the mean directions at Site 1218, computed separately for the normal and reverse polarity, are considerably different (Fig. 5). The reverse polarity mean inclination $\left(I_{\mathrm{R}}=-12.2\right)$ is significantly steeper than the normal polarity mean inclination $\left(I_{\mathrm{N}}=0.9\right)$ by $11.3^{\circ}$. In computing the average values of inclination, we removed samples with MAD values larger than $15^{\circ}$ and all samples within $5 \mathrm{~cm}$ from polarity transitions that could introduce biased directions. Data from core 1218B$4 \mathrm{H}$ and all discrete samples were also discarded. The mean inclinations were calculated using the method for inclination only $[19,20]$ to avoid any problem arising from poor precision of azimuthal orientation. The reason for this inclination asymmetry is unclear; incomplete removal of a soft overprint widespread in most of the samples is unlikely given the low MAD values obtained in the PCA analysis but it is reasonable to suspect that the asymmetry is related to the spurious high-coercivity component found in the AF demagnetization. The mean directions computed in the discrete samples set are $\mathrm{Dec}=349.0$, Inc $=14.8, \alpha_{95}=8.8$ and Dec=165.6, Inc $=2.9, \alpha_{95}=8.9$ for normal and reverse polarity, respectively. Discrete samples, although made of a heterogeneous and small set, do not confirm the inclination bias observed in the u-channel supporting the hypothesis of its spurious origin. However, it is worth mentioning that a similar

Table 3

Short polarity events recognized in Site 1218

\begin{tabular}{llllll}
\hline Event & $\begin{array}{l}\text { Top } \\
\text { (section, cm) }\end{array}$ & $\begin{array}{l}\text { Bottom } \\
\text { (section, cm) }\end{array}$ & Within chron & $\begin{array}{l}\text { Depth } \\
(\mathrm{mcd})\end{array}$ & $\begin{array}{l}\text { Estimated duration } \\
(\mathrm{ka})\end{array}$ \\
\hline A & $1218 \mathrm{~B}-4 \mathrm{H}-4-38.0$ & $1218 \mathrm{~B}-4 \mathrm{H}-4-42.0$ & C4Ar & 32.75 & 23 \\
B & $1218 \mathrm{~B}-4 \mathrm{H}-4-94.0$ & $1218 \mathrm{~B}-4 \mathrm{H}-4-97.0$ & C4Ar.1r & 33.42 & 14 \\
C & $1218 \mathrm{~B}-6 \mathrm{H}-3-133.0$ & $1218 \mathrm{~B}-6 \mathrm{H}-3-138.0$ & C5Cr & 53.91 & 12 \\
D & $1218 \mathrm{~B}-6 \mathrm{H}-5-94.0$ & $1218 \mathrm{~B}-6 \mathrm{H}-5-98.0$ & C5Dr & 56.52 & 18 \\
E & $1218 \mathrm{~B}-7 \mathrm{H}-6-122.0$ & $1218 \mathrm{~B}-7 \mathrm{H}-6-128.0$ & C6r & 67.23 & 8 \\
F & $1218 \mathrm{~B}-8 \mathrm{H}-4-142.0$ & $1218 \mathrm{~B}-8 \mathrm{H}-4-149.0$ & C6Ar & 75.25 & 9 \\
\hline
\end{tabular}


phenomenon has been observed by Pares and Lanci [21] in ODP Site 1220, which also used AF demagnetization techniques on u-channel samples, and by Schneider and Kent [22,23] on discrete samples in cores of Plio-Pleistocene equatorial sediment where the effect was ascribed to a non-reversing quadrupole component of the geomagnetic field.

Whatever its cause, the inclination polarity bias should be removed to calculate the site paleolatitude. It is not possible to establish a priori if the bias in inclination affects preferentially one polarity without knowing the direction of the biasing component. However, since the component of the magnetization carrying the bias is a relatively small fraction of the ChRM (the maximum possible bias is smaller than $10^{\circ}$ ) we can assume, to the first order approximation, that it affects normal and reverse polarity in the same way. This assumption is especially appropriate if the bias is due to the steep high-coercivity component, which is nearly perpendicular to the directions. Using this simple approach the inclination bias was corrected by adding the values that restore the symmetry between mean paleomagnetic inclinations calculated within adjacent polarity chrons. The inclinations obtained indicate a linear trend from present-day inclination to near zero (equatorial) inclination in the late Oligocene-early Miocene. This average trend is slightly shallower than the value expected from paleolatitude of the Pacific plate through time $[3,4]$ but the difference is well within the uncertainty of about $\pm 3^{\circ}$ in latitude $\left( \pm 6^{\circ}\right.$ in inclination) due to the data scatter.

\section{Conclusion}

Site 1218 gave a continuous magnetostratigraphic record of the Miocene from an equatorial site. The magnetostratigraphy matches very closely the polarity pattern of the GPTS providing an accurate time frame for the Miocene at this site and the basis for future cyclostratigraphic dating and precise global correlations. The Pliocene-Miocene and Miocene-Oligocene boundaries can be easily identified, based on the magnetostratigraphy, at 22 and $96.5 \mathrm{mcd}$, respectively.

Six short-polarity intervals have been observed in the Miocene section of Site 1218, which do not have a counterpart in the CK95 GTPS and they do not correspond to any of the "cryptochrons" reported in the CK95 GPTS. The significance of these events as real geomagnetic reversals cannot be assessed based solely on the data presented here; however event $\mathrm{B}$ in chron C4Ar.1r and event $\mathrm{D}$ in chron C5Dr have been found elsewhere [17,18] suggesting that these two may represent true geomagnetic polarity subchrons.

The analysis of paleomagnetic inclinations supports current reconstruction models of Pacific plate movements within the uncertainty of $\pm 6^{\circ}$ in inclination.

\section{Acknowledgments}

We are grateful to Ann Hirt (ETH Zurich) and Leonardo Sagnotti (INVG Rome) for support in the measurement of part of the discrete samples and to Helen Evans for help with u-channel measurements. L. Sagnotti and an anonymous reviewer are thanked for helping in improving the manuscript. Phil Rumford and Bruce Horan, at the Gulf Coast Repository, were very helpful and patient with core sampling. This research used samples provided by the Ocean Drilling Program (ODP). The ODP is sponsored by the U.S. National Science Foundation (NSF) and participating countries under management of Joint Oceanographic Institutions (JOI), Inc. Funding for this research was provided by USSAC. LDEO contribution Number 6649.

\section{References}

[1] N.D. Opdyke, G. Channell, Magnetic Stratigraphy, Academic Press, New York, 1996, p. 346.

[2] Shipboard Scientific Party, Leg 199 summary, in: M.W. Lyle, P.A. Wilson, T.R. Janecek, et al., (Eds.), Proc. ODP, Init. Repts., vol. 199, Ocean Drilling Program, College Station TX, 2002, pp. $1-87$.

[3] A.E. Gripp, R.G. Gordon, Current plate velocities relative to the hotspots incorporating the NUVEL-1 global plate motion model, Geophys. Res. Lett. 17 (1990) 1109-1112.

[4] D.C. Engebretson, A. Cox, R.G. Gordon, Relative motions between Oceanic and Continental plates in the Pacific Basin, Spec. Pap. -Geol. Soc. Am. (1985) 206.

[5] L. Tauxe, J.L. LaBrecque, R. Dodson, M. Fuller, U-channels-a new technique for paleomagnetic analysis of hydraulic piston cores, EOS, Trans. Am. Geophys. Union 64 (1983) 219.

[6] Y. Guyodo, J.E.T. Channell, R. Thomas, Deconvolution of uchannel paleomagnetic data near geomagnetic reversals and 
short events, Geophys. Res. Lett. 29 (2002) 1845, (doi:10.1029/2002GL014963).

[7] H. Oda, H. Shibuya, Deconvolution of long-core paleomagnetic data of Ocean drilling program by Akaike's Bayesian information criterion minimization, J. Geophys. Res. 101 (1996) 2815-2834.

[8] W. Lowrie, Identification of ferromagnetic minerals in a rock by coercivity and unblocking temperature properties, Geophys. Res. Lett. 17 (1990) 159-162.

[9] R. Day, M. Fuller, V.A. Schmidt, Hysteresis properties of titanomagnetites: grain-size and compositional dependence, Phys. Earth Planet. Inter. 13 (1977) 260-267.

[10] R.A. Fisher, Dispersion on a sphere, Proc. R. Soc. Lond. A217 (1953) 295-305.

[11] J.L. Kirschvink, The least-squares line and plane and the analysis of paleomagnetic data, Geophys. J. R. Astron. Soc. 62 (1980) 699-718.

[12] J.D.A. Zijderveld, A.C. demagnetization of rocks - analysis of results, in: D.W. Collinson, K.M. Creer, S.K. Runcorn (Eds.), Methods in Paleomagnetism, Elsevier, New York, 1967, pp. $254-286$.

[13] J. Gee, H. Staudigel, L. Tauxe, T. Pick, Y. Gallet, Magnetization of the La Palma Seamount Series: implications for seamount paleopoles, J. Geophys. Res. 9811 (1993) 743-768.

[14] S.C. Cande, D.V. Kent, Revised calibration of the geomagnetic polarity time scale for the Late Cretaceous and Cenozoic, J. Geophys. Res. 100 (1995) 6093-6095.

[15] N.J. Shackleton, S. Crowhurst, T. Hagelberg, N.G. Pisias, D.A. Schneider, A new Late Neogene time scale: application to Leg 138 sites, Proceedings of the Ocean Drilling Program, Sci. Res. 138 (1995) 73-90.
[16] F.F. Steininger, M.P. Aubrey, M. Biolzi, A.M. Borsetti, F. Cati, F. Corfield, R. Gelati, S. Iaccarino, G. Napoleone, F. Rogl, R. Rotzel, S. Spezzaferri, F. Tateo, G. Villa, D. Zevenboom, Proposal for the global stratotype section and point (GSSP) for the base of the Neogene (the Paleogene/ Neogene boundary), in: A. Montanari, et al. (Eds.), Miocene Stratigraphy: An Integrated Approach, Elsevier, Amsterdam, 1997, pp. $125-147$.

[17] E.T. Channell, S. Galeotti, E.E. Martin, K. Billups, H. Scher, J.S. Stoner, Eocene to Miocene magnetostratigraphy, biostratigraphy, and chemostratigraphy at ODP Site 1090 (subAntarctic South Atlantic), Geol. Soc. Am. Bull. 115 (2003) $607-623$.

[18] W. Krijgsmann, D.V. Kent, Non-uniform occurrence of shortterm fluctuations in geomagnetic field? New results from Middle to Late Miocene sediments of the North Atlantic (DSDP Site 608), AGU Monograph (2004) (in press).

[19] P.L. McFadden, A. Reid, Analysis of paleomagnetic inclination data, Geophys. J. R. Astron. Soc. 69 (1982) 307-319.

[20] D.A. Schneider, D.V. Kent, The time-averaged paleomagnetic field, Rev. Geophys. 18 (1990) 71-96.

[21] M.J. Pares, L. Lanci, A complete Middle Eocene-Early Miocene magnetic polarity stratigraphy in Equatorial Pacific sediments (ODP Site 1220), AGU Monograph (2004) (in press).

[22] D.A. Schneider, D.V. Kent, The paleomagnetic field from equatorial deep-sea sediments: axial symmetry and polarity asymmetry, Science 242 (1988) 252-256.

[23] D.A. Schneider, D.V. Kent, Inclination anomalies from Indian Ocean sediments and the possibility of a standing nondipole field, J. Geophys. Res. 93 (1988) 11621-11630. 